\title{
Competitividade e gap tecnológico - uma análise comparativa entre Brasil e países europeus selecionados*
}

\author{
Tatiana Massaroli Melo** \\ André Luiz Correa*** \\ Enéas Gonçalves Carvalho **** \\ Mario Luiz Possas*****
}

Recebido: 07/04/2015 Versão Revisada (entregue): 10/08/2016 Aprovado: 17/08/201

\section{RESUMO}

Este artigo analisa os padrões de comportamento inovativo de diferentes países, com o propósito de verificar a existência de um gap tecnológico entre o Brasil e os países tecnologicamente mais dinâmicos desta amostra, os quais serão chamados de fronteira tecnológica. A metodologia proposta consiste na análise de correspondência, realizada por meio um conjunto de indicadores de inovação elaborados a partir da Pesquisa de Inovação Tecnológica (Pintec), do IBGE, e do Community Innovation Survey (CIS). Com base em quatro indicadores de inovação setoriais construídos para o Brasil e um conjunto de dez países europeus, foram elaboradas as análises de correspondência, considerando as dimensões país-indicador e setor-indicador.

* Os autores agradecem o trabalho do corpo editorial e da secretaria executiva da RBI, bem como os comentários de dois pareceristas anônimos.

** Faculdade de Ciências e Letras/Universidade Estadual Paulista (FCLAr/UNESP), Araraquara (SP), Brasil. Email: tmassaroli@ fclar.unesp.br

*** Faculdade de Ciências e Letras/Universidade Estadual Paulista (FCLAr/UNESP), Araraquara (SP), Brasil. Email: andrelc@fclar. unesp.br

**** Faculdade de Ciências e Letras/Universidade Estadual Paulista (FCLAr/UNESP), Araraquara (SP), Brasil. Email: egcarvalho58@ gmail.com

*****Faculdade de Ciências e Letras/Unesp e Instituto de Economia/UFRJ, Brasil. Email: mariopossas@gmail.com 
PalaVras-CHAVE | Capacitações Tecnológicas; Competitividade; Gap Tecnológico; Indicadores de Inovação

Códigos JEL | O31; O32; O33

\title{
Competitiveness and technological gap - a comparative analysis between Brazil and selected European countries
}

\begin{abstract}
This paper analyzes the innovative behavior patterns of different countries in order to verify the existence of a technological gap between Brazil and the technologically most dynamic countries in the sample, which will be called technological frontier. The proposed methodology consists of correspondence analysis, performed from a set of innovation indicators based on Technological Innovation Survey (PINTEC) IBGE and the Community Innovation Survey (CIS). Based on four sectoral innovation indicators built for Brazil and a set of ten European countries, correspondence analysis was prepared considering the following dimensions: (i) country-indicator; (ii) industry-indicator.
\end{abstract}

KeYwords | Technological Capabilities; Competitiveness; Technological Gap; Innovation Indicators

JEL-CODES | O31; O32; O33 


\section{Introdução}

Este artigo analisa os padrões de comportamento inovativo de diferentes países, com o propósito de verificar a existência de um gap tecnológico entre o Brasil e os países tecnologicamente mais dinâmicos desta amostra, os quais serão chamados de fronteira tecnológica. A metodologia proposta consiste na análise de correspondência, realizada por meio de um conjunto de indicadores de inovação elaborados a partir da Pesquisa de Inovação Tecnológica (Pintec), do IBGE, e do Community Innovation Survey (CIS). Com base em quatro indicadores de inovação setoriais construídos para o Brasil e um conjunto de dez países europeus, foram elaboradas as análises de correspondência, considerando as dimensões país-indicador e setor-indicador.

O ponto de partida para o desenvolvimento das análises de correspondência foi a relação entre desempenho tecnológico e competitividade industrial, considerando o desempenho tecnológico como dependente do desenvolvimento de competências produtivas e tecnológicas e a competitividade como o resultado da capacidade das empresas para reduzir o hiato tecnológico diante dos concorrentes no mercado internacional. Dessa forma, somente o desenvolvimento de capacidades produtivas e tecnológicas na atividade industrial permite elevar a capacidade de um país para competir no mercado internacional. Esta afirmação torna-se evidente quando a abordagem lança mão de indicadores de esforço de inovação que traduzem o hiato tecnológico entre Brasil e um conjunto de países europeus selecionados.

Os resultados das análises de correspondência evidenciam a existência de um forte gap tecnológico entre Brasil e os países tecnologicamente mais dinâmicos da amostra, com baixa presença de empresas inovadoras em produto e processo nos setores de elevado desempenho inovativo, ${ }^{1}$ como farmacêutico, equipamentos de informática, produtos químicos e produção de máquinas e equipamentos elétricos.

A seguir é apresentado um referencial teórico sobre a relação entre competitividade e hiato tecnológico, com ênfase na abordagem evolucionista. Posteriormente são discutidos os resultados das análises de correspondência, mostrando o gap tecnológico entre Brasil e os países europeus selecionados. Por fim, são colocadas as principais conclusões. 1 A classificação da intensidade tecnológica dos setores segue os critérios estabelecidos pela OCDE. De acordo com esta classificaçāo,
é possível distinguir os setores nas categorias baixa, média e alta intensidade tecnológica. 


\section{Competitividade e hiato tecnológico}

A relação entre desempenho tecnológico, competitividade e crescimento econômico tem sido amplamente analisada pela literatura econômica (ANTIMIANI; CONSTANTINI, 2013; FAGERBERG; SRHOLEC, 2008; FAGERBERG et al., 2007; FAGERBERG, 1994; DOSI; SOETE, 1988; NELSON; WINTER, 1982; POSNER, 1961). As análises mais interessantes frequentemente são aquelas encontradas fora da abordagem tradicional (mainstream), por sua melhor caracterização tanto do fenômeno do progresso técnico quanto das instituiçōes e agentes envolvidos.

De acordo com Castellacci (2008, p. 990-991), a hipótese de gap tecnológico é sustentada pelo argumento de que a inovação é o maior determinante do desempenho de uma indústria ou país nos mercados internacionais, com foco nos impactos da atividade inovativa sobre a dinâmica da produtividade do trabalho no nível macroeconômico. Alguns estudos empíricos corroboram a ideia de que fatores não-preço, tais como o desenvolvimento de atividades inovativas por parte das empresas e as especificidades setoriais que influenciam a criação e difusão do conhecimento, têm sido significativamente mais relevantes do que as variáveis relacionadas a preço. Belderbos, Duvivier e Wynen (2009) encontraram evidências de que firmas mais inovativas são mais intensivas em exportações do que as não inovativas. Damijan et al. (2008) mostram que as atividades inovativas da empresa reforçam sua probabilidade de se tornar exportadora e que, uma vez alcançado o mercado internacional, manter ou ampliar o market share exportado requer maior esforço inovativo e ganhos de produtividade. As evidências encontradas pelos autores vão em duas direções, indicando que existe a causalidade tanto do esforço inovativo para desempenho exportador quanto o contrário, do desempenho exportador levando ao maior esforço inovativo. Independentemente da direção da causalidade, há evidências de que a capacidade inovativa da firma, seja adotando estratégias de inovação ou imitação, é um importante fator para a manutenção e ampliação de seu market share exportado, sendo elemento fundamental da competitividade empresarial.

Uma das maiores dificuldades ao se tentar abordar a noção de competitividade decorre da sua complexidade intrínseca. A não ser para enfoques muito restritivos e heroicos, a competitividade resulta de um processo complexo e que tem múltiplos determinantes. Ademais, a sua mensuração - a construção de indicadores de competitividade - tem se revelado um exercício que enfrenta inúmeras dificuldades ${ }^{2}$ (DOSI et al., 1990; OECD, 1992).

2 "Qualquer destes indicadores pode ser influenciado por outros fatores que não [pela] competitividade" (OECD, 1992, p. 242). 
Quanto aos determinantes da competitividade, a abordagem das capacidades (ou capacitações) dinâmicas, proposta inicialmente por Teece e Pisano (1994), parece conter os elementos mais apropriados para explicar o êxito competitivo da empresa. Nessa perspectiva, a competitividade resultaria dos processos organizacionais e administrativos (ou "rotinas") implementados, das posiçōes (ou ativos, no sentido amplo) alcançadas e das trajetórias tecnológicas seguidas pelas empresas (TEECE, 2007; TIDD et al., 2008).

Adotando-se a perspectiva de que o mercado é o locus privilegiado da concorrência intercapitalista - isto é, de que ele é o âmbito do processo de interação das unidades econômicas em sua busca contínua por lucros, a partir do esforço inovativo incessante -, parece apropriado considerar o mercado o espaço no qual a competitividade de cada agente é determinada (SCHUMPETER, 1942; POSSAS, 1987).

Tal opção não implica nem tomar a competitividade como tendo lugar de forma isolada - "a competitividade deriva da interação entre firmas, regiôes, países e do suporte do sistema setorial que conecta estes diferentes níveis de análise" (CANTWELL, 2005, p. 551) -, nem descartar as possibilidades analíticas de abordar a competitividade internacional de uma forma mais abrangente, isto é, em termos do conjunto do setor industrial ou mesmo de um país (MOWERY; NELSON, 1999; NELSON, 1993; OECD, 1992 ).

Uma definição de competitividade nacional consistente com as considerações anteriores, e que se tornou muito influente entre os economistas heterodoxos, foi adotada pela OECD (1992). ${ }^{3}$ A partir do referido estudo, pode-se propor que a competitividade de uma economia nacional é mais do que a simples soma da competitividade coletiva ou "média" de suas empresas, estando também relacionada aos seus padrões setoriais de produção e à sua respectiva inserção no mercado internacional. A competitividade de uma nação também resulta de tendências de longo prazo, específicas aos países, da força e influência das estruturas produtivas nacionais, de seu sistema de inovação, de sua infraestrutura técnica e de outras externalidades, com base nas quais suas empresas constroem as respectivas capacidades dinâmicas e desenvolvem os atributos básicos da sua competitividade. Para manter ou aumentar sua posição competitiva, a firma deve ser capaz de construir capacidades dinâmicas, isto é, perceber a necessidade de recombinar recursos em face das mudanças em seu ambiente (PELAEZ et al., 2008).

3 "Competitividade para uma nação é o grau com que ela pode, sob condiçōes de mercado justo e livre, produzir bens e serviços que passem no teste dos mercados internacionais ao mesmo tempo em que mantém [ou] expande a renda real dos seus cidadãos. Competitividade é a base para um padrão de vida nacional. É também fundamental para a expansão das oportunidades de emprego e para permitir que a naçāo cumpra adequadamente com suas obrigaçôes internacionais" (OECD, 1992, p. 247). 
Nesse contexto, o desenvolvimento da estratégia imitativa, fruto das habilidades para explorar a difusão internacional de tecnologias, é apontado por Castellacci (2008) como importante elemento para o desempenho competitivo de setores e países. O processo de imitação requer consideráveis esforços para construir uma estrutura industrial tecnologicamente avançada, necessária para a consolidação de capacidade de absorção e da habilidade para imitar tecnologias estrangeiras mais avançadas. Com base nesse processo, as firmas de determinado setor são capazes não apenas de desenvolver domesticamente as tecnologias estrangeiras, mas também de dinamizar elos na cadeia de produção, tais como entre fornecedores, produtores e usuários, alcançando, em estágios iniciais, diferenciais competitivos no mercado interno, em termos de aumento de market share, para posteriormente competir no mercado internacional.

Para Posner (1961), o progresso técnico é capaz de romper, abruptamente, com posições de mercado estabelecidas, possibilitando o surgimento de novos atores liderando a competição por mercados internacionais. Nesse sentido, muitos autores têm argumentado que a tecnologia é um dos elementos cruciais para compreender a origem dos diferenciais competitivos entre os países. Segundo Dosi et al. (2014), economias capazes de produzir inovações de produto e processo estão mais aptas para ganhar ou manter posiçōes competitivas no comércio internacional. Para os autores, estas duas formas de inovação afetam a competitividade da firma de diferentes formas. Enquanto as inovaçôes de processo estão frequentemente associadas a significativos ganhos de produtividade, as inovações de produto, relacionadas à diferenciação de produto ou melhoria de qualidade, auxiliam a empresa a conquistar ou, até mesmo, criar novos mercados. Dessa forma, o esforço de um país para aumentar sua competitividade deve passar, necessariamente, pela redução de seu hiato tecnológico em relação aos países que apresentam melhor desempenho no comércio internacional.

Os trabalhos sobre hiato tecnológico mais frequentes na literatura analisam a relação entre taxas diferenciais de crescimento do PIB per capita, nos vários países, e suas taxas de progresso técnico. A tecnologia é entendida como fator incorporado à estrutura das organizaçôes, sendo a transferência entre elas difícil e custosa. A mudança tecnológica, portanto, é vista como o resultado conjunto de inovação e atividades de aprendizado dentro das organizaçōes, especialmente das firmas. Fatores específicos a cada país dão às tecnologias e ao processo de mudança tecnológica um caráter nacional ("tecnologia nacional"). Nesse sentido, a empresa assume o papel de principal indutor do progresso técnico, uma vez que as capacitaçôes produtivas e tecnológicas se localizam em seu âmbito (FAGERBERG, 1994). 
Para Fagerberg e Verspagen (2013), embora os países em desenvolvimento apresentem maiores possibilidades de crescimento, como é o caso de China e Índia, em relação às economias desenvolvidas, a transformação deste crescimento potencial em crescimento real passa pelo importante desafio de construir capacitaçôes para explorar as oportunidades para o catching up econômico e tecnológico, traduzido em ganhos de competitividade. A relação entre competitividade e hiato tecnológico pode ser esboçada do seguinte modo: se a inovação está relacionada à modificação nos padrōes de produção existentes (SCHUMPETER, 1942), determinando vantagens diferenciais para o inovador, a manutenção ou expansão da competitividade (a capacidade de competir) depende não apenas de competências produtivas, mas, principalmente, de competências para gerar e administrar a mudança técnica (BELL; PAVITT, 1995, p. 76-77; LALL, 1992) em ritmo igual ou superior ao dos concorrentes. O hiato tecnológico interessa, nesse contexto, diretamente como medida de distância entre o nível tecnológico de um país vis-à-vis seus concorrentes, mais do que como explicação para os níveis diferenciais de renda per capita, como é usual na literatura.

Considerando o argumento de Dosi e Soete (1983), o que explica grande parte da liderança tecnológica dos países desenvolvidos em relação àqueles em desenvolvimento é a existência de assimetrias tecnológicas que, por sua vez, estão associadas com o desenvolvimento da estrutura produtiva de cada país e com a capacidade dessa estrutura de introduzir bens, serviços, processos, etc., que os outros países não são capazes de produzir, independentemente do custo. Analisando os países desenvolvidos, Bell e Pavitt (1995) argumentam que a transferência de tecnologia e know-how produtivo não é suficiente para conquistar e manter uma boa posição competitiva. É preciso investimento em capacitação tecnológica para gerar mudanças na produção, a fim de manter ou aumentar a competitividade. Ao encerrar seu texto, os autores pontuam que "o volume e a eficácia destes investimentos, que são principalmente específicos às firmas, dependem da competência tecnológica, da direção, da qualificação da força de trabalho, dos incentivos que as firmas têm para investir em acumulação tecnológica e da eficácia das instituiçôes de apoio especializadas" (BELL; PAVITT, 1995, p. 101). Para os autores, tais instituições são os laboratórios de P\&D, mas poderíamos estender a noção para todo o sistema nacional de inovação.

Contrariando as teorias tradicionais que preveem ganhos da especialização das economias no comércio internacional, evidências têm apontado que as assimetrias tecnológicas entre países, resultado da especialização, afetam negativamente o desempenho competitivo dos latecomers no comércio mundial (DOSI; SOETE, 1983; DOSI; PAVITT; SOETE, 1990; AMENDOLA et al., 1993). Elas sugerem 
que as capacitações tecnológicas relativas de cada economia, em cada setor, são um poderoso determinante da parcela de exportação daquele país, naquele setor, no mercado mundial. Dessa forma, a parcela das exportaçôes indica a competitividade de cada país e esta depende da capacitação tecnológica. De acordo com Tigre (2002, p. 249), a competitividade internacional está, em grande medida, ligada ao crescimento de novas indústrias, à busca de economias de escala dinâmicas, às inovaçôes de processo e ao fomento de atividades científicas e tecnológicas.

\section{Indicadores de competitividade internacional e a análise do gap tecnológico brasileiro}

A questão da mensuração da competitividade é difícil porque, por um lado, não existe indicador único e, por outro, qualquer indicador pode ser afetado por elementos estranhos (espúrios) à noção de competitividade. ${ }^{4}$ De fato, em razão da complexidade intrínseca da noção de competitividade, decorrente da sua determinação múltipla e da componente qualitativa de algumas de suas fontes, não parece plausível, em geral, que um único indicador seja suficiente para medir, com precisão, a competitividade relativa de um agente, em um ambiente competitivo, num dado período de referência (DOSI et al., 1990; OECD, 1992; LALL, 2001; FAGERBERG, 2002).

Com base nestas considerações, parece mais adequado propor a utilização simultânea de mais de um indicador, como um critério geral, para se efetuar a avaliação da competitividade, até porque os indicadores também costumam ser afetados (e distorcidos) por fatores espúrios, como, por exemplo, uma taxa de câmbio excessiva e artificialmente desvalorizada, a existência de subsídios às exportaçōes, etc.

\subsection{Análise do gap tecnológico brasileiro}

Como uma tentativa exploratória de verificação da distância entre atividades tecnológicas realizadas no Brasil e nos países desenvolvidos, será apresentado a seguir um conjunto de indicadores. Para tanto, foram selecionados quatro indicadores de inovação em 11 setores da atividade industrial no Brasil e em dez países europeus: Bélgica, Rússia, Alemanha, Espanha, França, Croácia, Itália, Hungria, Holanda e

4 Ainda com relação aos indicadores de competitividade, parece possível classificá-los em dois grupos amplos: indicadores de desempenho e de eficiência. O primeiro deles é composto pelos indicadores de desempenho de vendas, de penetração de mercados (market-share) e de rentabilidade (margens e taxas de lucro). O segundo grupo é formado pelos indicadores de eficiência produtiva - coeficientes técnicos e/ou de produtividade física - e de eficiência econômica - produtividade em valor (POSSAS, 1999). 
Sérvia. 5 Os indicadores foram construídos com dados extraídos do Community Innovation Survey para 2010 e da Pesquisa da Inovação Tecnológica (Pintec/IBGE) para 2011. A opção por restringir a pesquisa em apenas um período deve-se à dificuldade de obter dados para todos os países e setores selecionados em mais do que uma edição de publicação do CIS. Dado o caráter voluntário desta pesquisa, observou-se a inexistência de informações para muitos dos países selecionados, sobretudo os do leste europeu, na comparação entre as duas pesquisas, CIS e Pintec, num período superior a um ano.

Os indicadores são definidos a seguir, com base no Manual da Pintec (IBGE, 2011) e no Manual Frascati OECD (2002). Neste último, a P\&D é apenas uma etapa do processo de inovação que inclui "o trabalho criativo levado a cabo de forma sistemática para aumentar os campos de conhecimentos [...] e a utilização desses conhecimentos para criar novas aplicações" (OECD, 2002; cap. 2, p. 43). Nessa perspectiva, a inovação tecnológica engloba tanto a P\&D formal, realizada nos laboratórios de P\&D, como a informal ou ocasional, produzida em outras unidades e nas diferentes atividades. Os indicadores de inovação utilizados nesta pesquisa são os seguintes:empresas que realizaram atividades internas de $\mathrm{P} \& \mathrm{D}$ em relação ao total de empresas em cada setor selecionado (PDI): compreende o trabalho criativo, com o objetivo de aumentar o conhecimento e o uso desses conhecimentos para desenvolver novas aplicações, tais como produtos ou processos novos ou substancialmente aprimorados. O design, a construção e o teste de protótipos e de instalações-piloto constituem, muitas vezes, uma das fases mais importantes das atividades de P\&D. Nessas atividades, está incluído também o desenvolvimento de software, desde que envolva avanço tecnológico ou científico;

- empresas que inovaram em produto e/ou processo em relação ao total de empresas em cada setor selecionado (EIN): uma inovação de produto ou processo consiste na introdução de um produto (bem ou serviço) ou processo novo ou substancialmente aprimorado (IBGE, 2011, p. 5, 8);

- $\quad$ pesquisadores ocupados em atividades de P\&D (PO), incluindo apenas pessoal ocupado com nível de escolaridade igual ou superior à graduação;

- total dos gastos relacionados às atividades de inovação (P\&D interno; P\&D externo; aquisição de conhecimento externo; aquisição de máquinas, equipamentos e software; treinamento) em relação ao faturamento líquido dos

5 O CIS é um survey aplicado de forma voluntária às empresas dos países da Comunidade Europeia. A Pintec é uma pesquisa compatível aplicada às empresas brasileiras. O caráter voluntário do CIS provoca ausência de informaçôes em alguns países em certos anos e setores. Por isso, os setores e países foram selecionados conforme a disponibilidade que os tornasse comparáveis. 
setores selecionados (gastos com inovação - GIN).Esses indicadores foram construídos a partir das respostas dos questionários disponibilizados pelas pesquisas Pintec e CIS. ${ }^{6}$ Em função da necessidade de compatibilidade entre as informações oferecidas por ambas as pesquisas, apresenta-se no Quadro 1 um resumo mostrando a origem das informaçôes coletadas, bem como a existência de compatibilidade entre elas. Para efeito de avaliação, foi construída uma escala de intensidade tecnológica para cada indicador. O critério para agrupar os setores nos grupos de baixa, média baixa, média alta e alta intensidade tecnológica foi baseado na distribuição dos dados, considerando os quartis da distribuição. Este critério de classificação limita-se ao conjunto de dados utilizados neste artigo e tem o propósito de verificar a distribuição de cada indicador, considerando tanto a dimensão setorial quando a dimensão nacional. É importante deixar claro que este critério de classificação é completamente diferente daquele adotado pela OECD para classificar setores segundo a intensidade tecnológica, que considera basicamente indicadores que refletem a intensidade de P\&D dos setores industriais. A classificação da OECD por intensidade tecnológica é baseada nos seguintes indicadores: gastos em P\&D em relação ao valor adicionado; gastos em $\mathrm{P} \& \mathrm{D}$ em relação à produção; e gastos em $\mathrm{P} \& \mathrm{D}$ mais tecnologia incorporada nos bens intermediários e de capital em relação à produção $(\mathrm{OECD}, 2005$, p. 170). A classificação da OECD é internacionalmente adotada e será aqui utilizada na seção de apresentação e análise dos resultados.

A construção de categorias de análise, segundo critério de intensidade tecnológica, proposta neste artigo foi feita a partir da avaliação das distribuições dos quatro indicadores de inovação selecionados, permitindo o agrupamento não apenas dos setores, mas também dos países investigados. Dessa forma, foi possível agrupar países e setores em quatro categorias de análise, a partir da investigação dos resultados em cada quartil da distribuição, conforme a seguinte classificação:

- quartil 1 - setores de baixa intensidade tecnológica;

- $\quad$ quartil 2 - setores de média baixa intensidade tecnológica;

- quartil 3 - setores de média alta intensidade tecnológica;

- quartil 4 - setores de alta intensidade tecnológica.

Com base nesta classificação, foi aplicada a metodologia de análise de correspondência, descrita na seção seguinte.

6 Os resultados dos indicadores construídos a partir das bases CIS (2010) e PINTEC (2011) são apresentados no Anexo. 


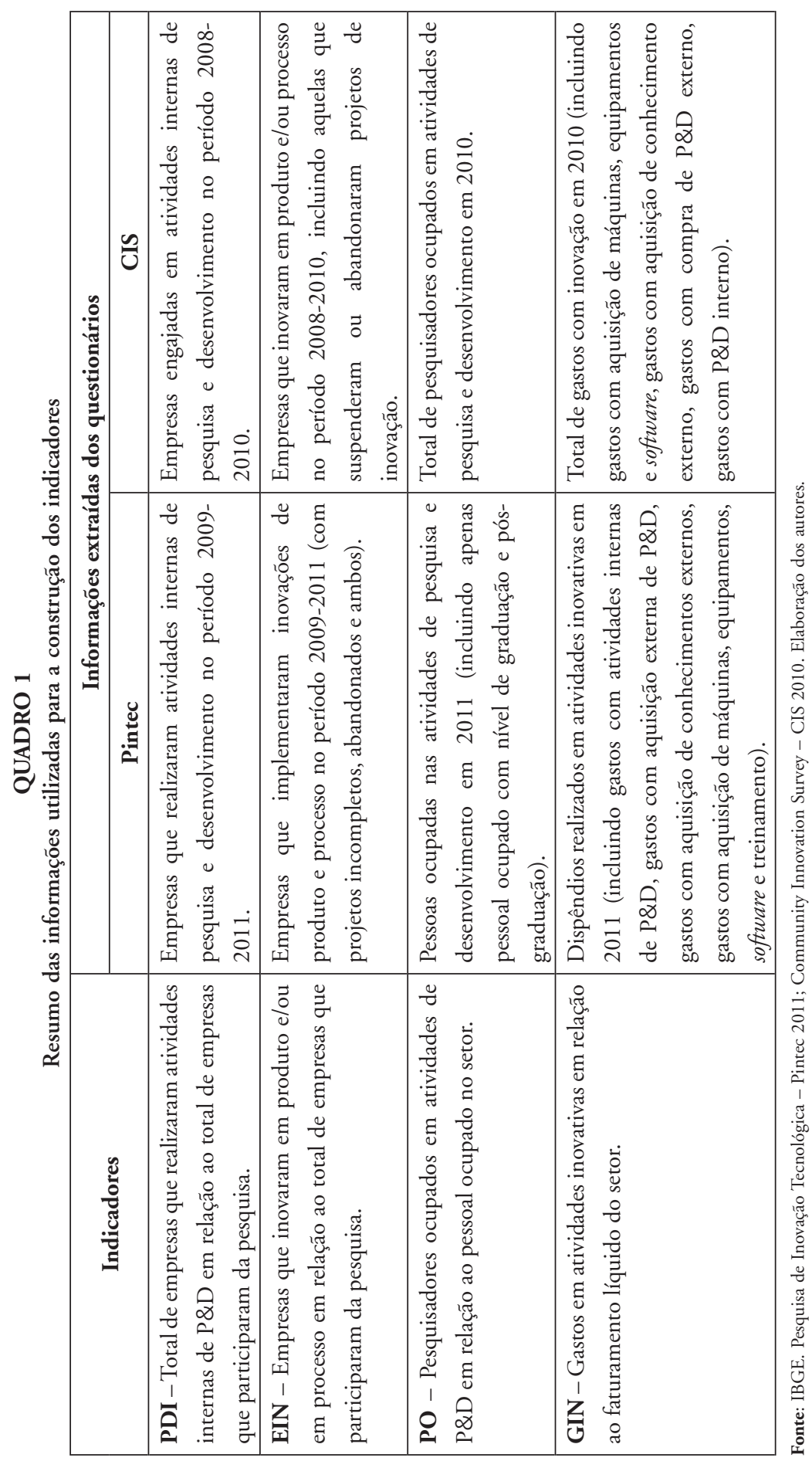




\subsection{Procedimentos metodológicos}

Para atingir os objetivos deste trabalho, será aplicada a técnica estatística de análise de correspondência. De maneira sucinta, pode-se entender a análise de correspondência como um método para estudar relações entre as categorias que compõem variáveis de natureza qualitativa, tais como intensidade tecnológica, setor ou país. Hair et al. (2005) destacam a utilização crescente deste método como forma de reduzir a dimensão de um conjunto de variáveis e representar visualmente as relações entre as categorias a partir de mapas e diagramas.

A aplicação da análise de correspondência parte da representação dos dados em uma tabela de contingência, de forma que as categorias de uma variável estejam em linhas (por exemplo, o país ou o setor) e as categorias da outra variável estejam em colunas (por exemplo, a intensidade tecnológica). A partir daí procura-se representar a associação entre as categorias das variáveis geometricamente, por meio do cálculo de distâncias e projeçôes ortogonais das categorias. ${ }^{7}$ A aplicação da análise de correspondência não necessita, a priori, de nenhuma hipótese restritiva acerca da estrutura de dados. A única condição necessária é que os valores das variáveis sejam não negativos. Não é essencial, mas em determinados contextos em que se procura avaliar a interdependência entre as variáveis, pode-se utilizar o teste de $\chi^{2}$ associado ao método.

Conforme Greenacre (2008), a análise de correspondência é análoga ao método de componentes principais, com a diferença de que na análise de correspondência os dados são de natureza qualitativa, ao passo que no método de componentes principais os dados são de natureza quantitativa. O método de componentes principais consiste, em linhas gerais, em obter combinaçóes lineares (componentes) das variáveis que expliquem o máximo de variância possível. $\mathrm{Na}$ análise de correspondência a representação dos dados ocorre em gráficos, cujos eixos representam componentes (ou dimensóes) associados à porcentagem de variância explicada do conjunto de dados. Mais precisamente, os dois componentes apresentados em cada diagrama correspondem às representaçôes reduzidas dos dados que melhor explicam a variabilidade do conjunto. Por fim, a partir da análise dos diagramas pode-se determinar a associação entre as categorias representadas por seus respectivos pontos.

Do ponto de vista da técnica, a análise de correspondência aplicada neste trabalho destaca a abordagem geométrica proposta nas equações (2) e (3). Formalmente,

7 O trabalho de Greenacre e Hastie (1987) apresenta os detalhes técnicos do método, destacadamente aqueles associados à repre-
sentaçăo geométrica da análise de correspondência. 
considere uma tabela de contingência $N(I \times J)$ em que $n_{i+}$ e $n_{+j}$ correspondem, respectivamente, aos totais da linha e da coluna. Seja $n$ o total de observaçôes. Considere a matriz $P$ de proporções relativas com elementos $p_{i j}$ dados por:

$$
p_{i j}=\frac{n_{i j}}{n_{++}}
$$

Onde $n_{++}$corresponde ao número total de observações.

$\mathrm{O}$ vetor $\left[a_{i}=\frac{n_{i 1}}{n_{i+}} \ldots \frac{n_{j}}{n_{i+}}\right]$ é denominado perfil linha e o vetor $\left[r=\frac{n_{1+}}{n} \ldots \frac{n_{I_{+}}}{n}\right]$ é denominado vetor de massas da linha. O vetor $r$ representa também o centroide dos perfis coluna. De maneira análoga, o vetor $\left[c=\frac{n_{+1}}{n} \ldots \frac{n_{+J}}{n}\right]$ corresponde ao vetor de massas das colunas e o centroide dos perfis linha. As distâncias entre os perfis linha são definidas pela métrica euclidiana ponderada dada por:

$$
\mathbf{d}_{\mathrm{C}}\left(\mathbf{a}_{\mathbf{i}}, \mathbf{a}_{\mathbf{i}}^{\mathrm{T}}\right)=\left(\mathbf{a}_{\mathbf{i}}-\mathbf{a}_{\mathbf{i}}^{\mathrm{T}}\right) \mathbf{D}_{\mathrm{C}}^{-1}\left(\mathbf{a}_{\mathbf{i}}-\mathbf{a}_{\mathbf{i}}^{\mathrm{T}}\right)
$$

Em que $D c$ é uma matriz diagonal composta pelas massas das colunas. De maneira análoga, as distâncias entre os perfis linha são ponderadas pela matriz $D r$, composta pelas massas das linhas em sua diagonal. Geometricamente, como há dependência linear entre as coordenadas dos perfis, os pontos estarão contidos no simplex com vértices na unidade dos eixos. A distância entre os perfis linha e o centroide c é dada por:

$$
\mathbf{d}_{\mathrm{C}}\left(\mathbf{a}_{\mathbf{i}}, \mathbf{c}\right)=\mathbf{n} \sum_{\mathrm{i}=1}^{\mathrm{J}} \mathbf{r}_{\mathbf{i}}\left(\mathbf{a}_{\mathbf{i}}-\mathbf{c}\right)^{\mathrm{T}} \mathbf{D}_{\mathrm{C}}^{-1}\left(\mathbf{a}_{\mathbf{i}}-\right.
$$

A média ponderada dos quadrados das distâncias entre os perfis linha e os centroides corresponde à estatística $\chi^{2}$ que pode ser utilizada para testar a independência entre linhas e colunas:

$$
\chi^{2}=\sum_{i=1}^{J} \sum_{J=1}^{I} \frac{\left(n_{\tilde{j}}-n_{i+} n_{+j} / n^{\prime}\right.}{n_{i+} n_{+j} / n}
$$

A quantidade $\chi^{2} / n$ é chamada de inércia total da matriz de dados. Pode-se encarar a análise de correspondência como uma forma de decompor a inércia total, de modo que seja possível representar os dados em um número reduzido de 
dimensões. A soma dos quadrados dos autovalores da matriz corresponde à inércia total, de modo que uma decomposição da inércia total é obtida a partir do quadrado dos autovalores individuais.

$$
\mathbf{Q}=\sum_{\mathrm{i}=1}^{\mathrm{I}} \mathbf{r}_{1}\left(\mathbf{a}_{\mathrm{i}}-\mathbf{c}\right)\left(\mathbf{a}_{1}-\mathbf{c}\right)^{\mathrm{T}} \mathbf{D}_{\mathrm{C}}^{-1}
$$

Neste trabalho realizaremos a análise de correspondência em duas etapas. Cumpre destacar que as variáveis setor e país são evidentemente qualitativas. Os indicadores, por sua vez, são variáveis quantitativas. Conforme destacado anteriormente, a construção de uma escala de intensidade tecnológica a partir dos quartis de cada distribuição permitiu representar os indicadores em categorias. Uma vez construída a escala, foi possível realizar os dois exercícios de análise de correspondência.

Primeiramente foi feita a análise de correspondência entre cada um dos indicadores e a variável país, de modo a avaliar a correspondência entre dinamismo inovativo e os países da amostra. Uma vez verificada a correspondência, efetuou-se uma nova análise de correspondência entre os indicadores de dinamismo inovativo e a variável setor, considerando os grupos de países formados no primeiro exercício. A seguir, apresenta-se a análise dos resultados.

\subsection{Resultados}

A Figura 1 apresenta os resultados da análise de correspondência entre os indicadores de dinamismo inovativo e a variável país.

Os mapas apresentados na Figura 1 agrupam os países segundo dinamismo inovativo (alto; médio alto; médio baixo; baixo), para cada um dos indicadores selecionados. Verifica-se que o Brasil possui semelhanças, do ponto de vista tecnológico, com os países europeus menos dinâmicos, como Hungria, Croácia e Sérvia, dividindo com estes o grupo de baixo dinamismo inovativo. $\mathrm{O}$ único indicador em que o Brasil apresenta desempenho satisfatório, por estar inserido no grupo de países com médio alto dinamismo inovativo, é o gasto com atividade inovativa (GIN). Apesar do bom desempenho do país, é importante salientar que este indicador considera não apenas os gastos em $\mathrm{P} \& \mathrm{D}$, mas também os gastos com atividades inovativas de modo mais amplo, incluindo aquisição de software e, sobretudo, aquisição de máquinas e equipamentos. É necessário lembrar que neste último item estão contabilizados os gastos com aquisição de equipamentos que não são inovaçōes para o mercado mundial, sendo, no máximo, novidade para a empresa ou 
para o mercado doméstico. Ao avaliarmos os países que estão nos grupos de alto e médio alto desempenho, observa-se a presença sistemática de Alemanha, Holanda e Bélgica, o que nos permite adotar tais países como a fronteira tecnológica, dente os investigados neste trabalho.

\section{FIGURA 1}

Mapas de distribuição de países, segundo intensidade inovativa

Brasil e países europeus selecionados -2010-2011
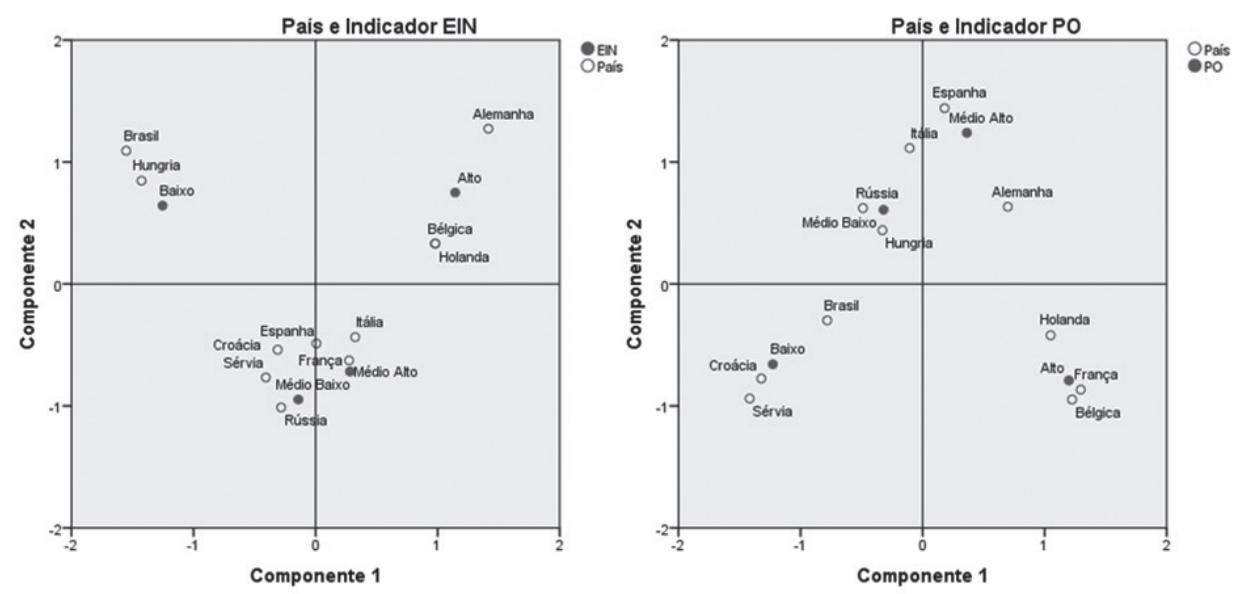

Fonte: IBGE. Pesquisa de Inovação Tecnológica - Pintec 2011; Community Innovation Survey - CIS 2010. Elaboração dos autores.

Com o propósito de investigar o desempenho desagregado de cada setor dentro de grupos de países selecionados a partir dos agrupamentos obtidos na Figura 1, a análise de correspondência foi aplicada para as dimensões indicador e setor. Os países foram separados em dois grupos, sendo o primeiro constituído por aqueles de baixo desempenho inovativo (Brasil, Hungria, Croácia e Sérvia) e o segundo grupo formado pelos de alto desempenho inovativo (Alemanha, Bélgica e Holanda). ${ }^{8}$

A Figura 2 apresenta os resultados da análise de correspondência para os países do grupo 1. É possível observar que nenhum setor se encontra no grupo de alto dinamismo inovativo. Curiosamente, os setores que, de acordo com o critério de intensidade tecnológica proposto pela $\mathrm{OECD}$, possuem alto e médio alto desempenho

8 A análise de correspondência para o indicador PDI não foi viabilizada porque, no caso dos países do primeiro grupo, todos os setores apresentaram desempenho baixo e, no caso dos países do grupo 2, todos os setores mostraram desempenho alto, não sendo possível encontrar diferentes agrupamentos. Para o indicador GIN, em virtude das suas deficiências para analisar o caso brasileiro, conforme apontado anteriormente nesta seção, decidimos não incorporá-lo nas análises setoriais. 
tecnológico - farmacêutico; equipamentos de informática e produtos eletrônicos; produtos químicos; veículos automotores - estão todos agrupados nas categorias baixo e médio baixo.

Quando os mapas da Figura 2 são comparados aos da Figura 3, que exibe os resultados dos países do grupo 2, observamos padrões diametralmente opostos. Enquanto nos mapas da Figura 2 não são encontrados setores agrupados na categoria alto desempenho tecnológico, na Figura 3 não se observam setores agrupados na categoria baixo. Tal evidência mostra que os países pertencentes ao grupo da fronteira (grupo 2) são caracterizados pela presença dos setores tecnologicamente dinâmicos, seguindo o critério da OECD, nas categorias corretas, ou seja, alto e médio alto desempenho tecnológico. A superioridade dos países do grupo 2 em relação aos do grupo 1 é revelada pela concentração de setores, tais como farmacêutico, produtos químicos, equipamentos de informática, máquinas e equipamentos elétricos e veículos automotivos, dentro das categorias alto e médio alto, sendo que estes mesmos setores foram agrupados de forma completamente oposta no caso dos países do grupo 1. Tal fato mostra a distância entre os países do grupo 1 e aqueles pertencentes ao grupo de fronteira, ou seja, Alemanha, Bélgica e Holanda.

\section{FIGURA 2}

Mapas de distribuição de setores, segundo intensidade inovativa - grupo 1

Brasil, Croácia e Sérvia - 2010-2011
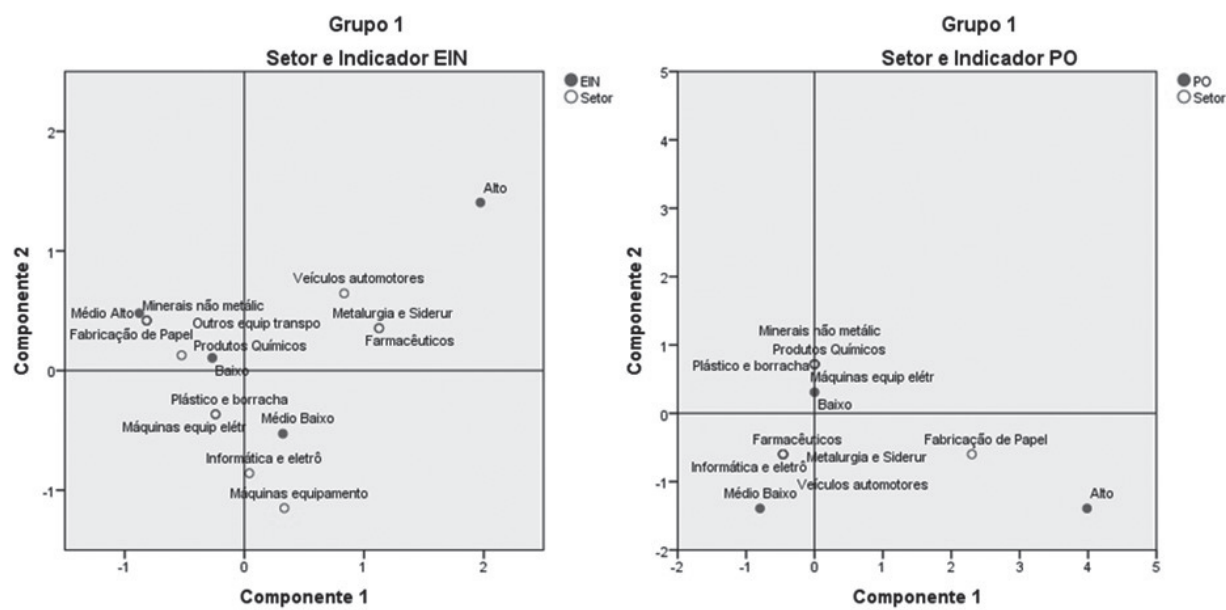

Fonte: IBGE. Pesquisa de Inovação Tecnológica - Pintec 2011; Community Innovation Survey - CIS 2010. Elaboraçāo dos autores. 
FIGURA 3

Mapas de distribuição de setores, segundo intensidade inovativa - grupo 2 Alemanha, Bélgica e Holanda -2010-2011
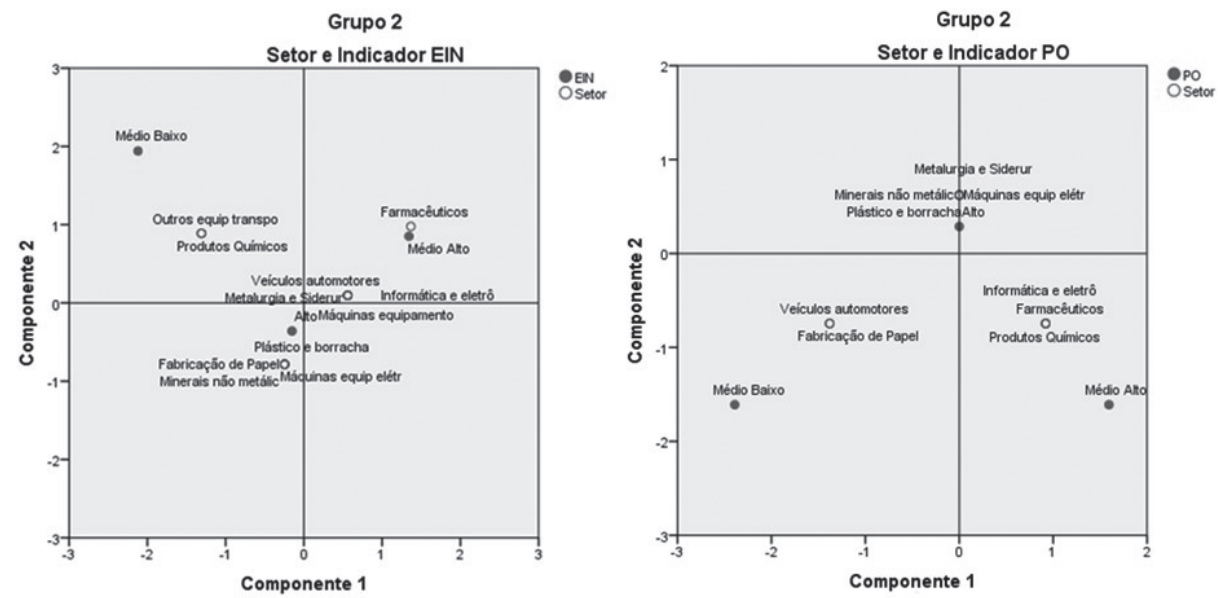

Fonte: IBGE. Pesquisa de Inovação Tecnológica - Pintec 2011; Community Innovation Survey - CIS 2010. Elaboração dos autores.

Um último elemento a ser considerado neste artigo é o comportamento do market share das exportações brasileiras em relação aos países investigados. A importância desta variável deve-se ao reconhecimento, sobretudo por parte dos autores da corrente neoschumpeteriana, conforme destacado na seção 2 , de que a capacidade inovativa da empresa está relacionada à manutenção ou ampliação de sua posição competitiva, expressa, entre outros fatores, no market share de suas exportaçôes. Assim, é possível argumentar que o desempenho inovador dos setores exerça alguma influência sobre o market share de suas exportaçōes, no sentido de aproximar as fatias de mercado de países que apresentam, entre outros fatores, o mesmo perfil inovador, tais como Alemanha, Bélgica e Holanda, distanciando-os de países com fraco esforço inovativo, como o Brasil.

A Tabela 1 apresenta a parcela das exportaçôes dos diferentes setores no mercado internacional e tem como objetivo comparar a posição competitiva do Brasil, por meio de suas exportações, com a dos países europeus mais bem posicionados, considerando a amostra de países analisada. Para tanto, é realizado um exercício meramente exploratório, mensurando a distância ou hiato, expressa em termos da diferença percentual, do market share das exportações brasileiras em relação aos demais países. A parcela das exportaçôes do setor i e país j no mercado internacional, ou market share, é mensurada da seguinte forma, com base nos dados extraídos do United Nations Commodity Trade Statistics Database (UN Comtrade): 


$$
M S X_{i j}=\frac{X_{i}^{j}}{X W_{i}}
$$

Onde:

$M S X_{i j}$ é o market share das exportaçôes do setor $i$ e país $j$;

$X_{i}^{j}$ corresponde às exportações do setor $i$ e país $j$ para o resto do mundo;

$X W_{i}$ compreende as exportações mundiais do setor $i$.

Os dados da Tabela 1 mostram um padrão bastante semelhante àquele revelado pela análise de correspondência, considerando exclusivamente indicadores de inovação. No caso do market share das exportações, a posição do Brasil em relação aos competidores europeus (Alemanha, Bélgica, Holanda, França, Espanha e Itália) indica grande discrepância na maioria dos setores investigados. Naqueles de alta intensidade inovativa, como fabricação de produtos químicos, farmoquímico e farmacêuticos, o Brasil apresenta a pior posição competitiva em relação aos países analisados. Em 2010, o hiato competitivo do Brasil no setor farmacêutico, em relação aos países com melhor posicionamento dentro da amostra, considerando a parcela das exportações no mercado mundial, foi de 98\% (Alemanha) e 97,4\% (Bélgica).

Os mapas obtidos a partir das análises de correspondência (Figuras 1 a 3) mostram que o Brasil não apenas se distancia tecnologicamente dos países europeus mais competitivos (Alemanha, Bélgica e Holanda), como também apresenta um padrão de esforço inovativo que é contrário àquele adotado nestes países. Enquanto este grupo realiza alto esforço inovativo nos setores de elevada intensidade tecnológica, o Brasil dispende poucos esforços de inovação nos mesmos setores. Um exemplo é o setor de produtos farmoquímicos e farmacêuticos, em que o Brasil empregou, em média, durante o triênio 2008-2010, apenas 1,9\% de pesquisadores em atividades de P\&D, contra 10,9\% na Bélgica e 5,5\% na Alemanha (Tabela 4 do Anexo).

Um setor em que o Brasil apresenta menor distância competitiva, em termos do market share das exportações, é o de alimentos, bebidas e tabaco. Nessa atividade, a parcela das exportações brasileiras no mercado mundial é $25 \%$ inferior à alemã, mas $52 \%$ superior ao market share da Bélgica. Ainda que o percentual de empresas que tenham declarado, entre 2008 e 2010, realizar atividades de P\&D interna seja muito baixo $-3,4 \%$ do total daquelas que participaram da Pintec -, a proporção de empresas que realizaram inovações, de produto ou processo, foi 


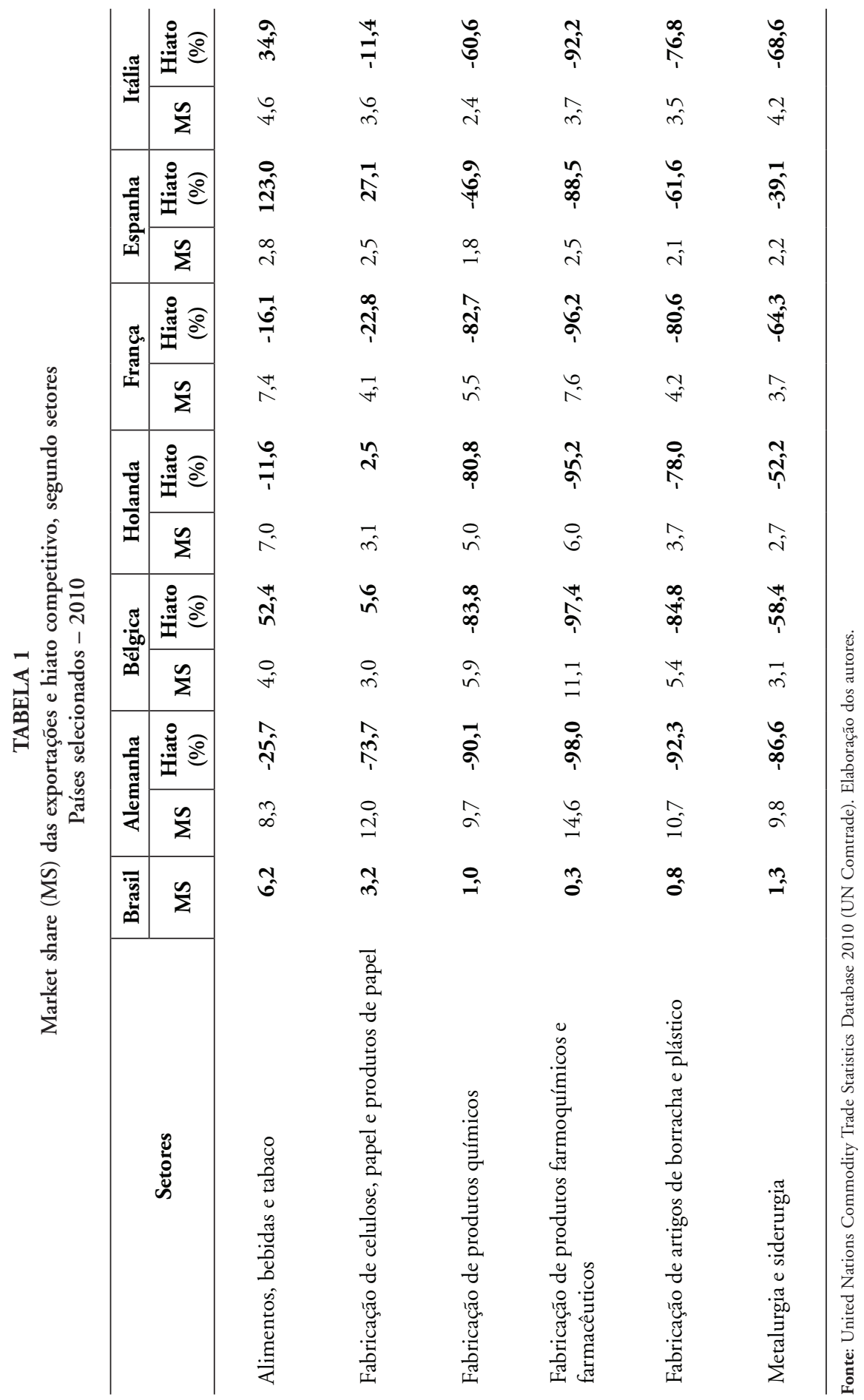


de $40 \%$, superior àquela encontrada na CIS para Alemanha $(19,5)$ e Bélgica $(18$, 4\%) (Tabela 1 do Anexo)

\section{Considerações finais}

Em linha com a teoria evolucionista, este artigo enfatiza as especificidades e a diversidade da estrutura industrial, traduzidas pelo dinamismo inovativo das empresas que caracteriza diferentes estruturas setoriais e, num nível mais agregado, diferentes padrões industriais nacionais. Esta capacidade de inovar e desenvolver padrôes de inovação é entendida como elemento decisivo para o desenvolvimento de competitividade da indústria, entendendo-se que a competitividade resulta, em grande medida, da capacidade de suas empresas para reduzir o hiato tecnológico em relação aos concorrentes no mercado internacional.

Somente o desenvolvimento de competências produtivas e tecnológicas na atividade industrial permite elevar a capacidade de um país para competir no mercado internacional. Esta afirmação torna-se evidente quando a abordagem lança mão de indicadores de esforço de inovação que traduzem o hiato tecnológico entre Brasil e um conjunto de países europeus selecionados.

A existência de grandes discrepâncias tecnológicas entre os grupos de países menos desenvolvidos, em que o Brasil se encontra, e os europeus mais dinâmicos, como Alemanha, Bélgica, França e Holanda, sobretudo nos setores de alta e média-alta intensidade tecnológica, segundo a classificação da OECD, é sintomática e provavelmente está relacionada ao hiato competitivo do país, em termos da parcela das exportaçōes industriais brasileiras no mercado internacional. Esta é uma hipótese de trabalho que o presente artigo procurou fundamentar e que será aprofundada em trabalhos futuros.

As análises de correspondência foram aplicadas neste estudo para as dimensões país-indicador e país-setor. No caso da análise país-indicador, observa-se a presença do Brasil junto com os demais países de desempenho inovativo baixo, tais como Hungria, Sérvia e Croácia, enquanto os mais dinâmicos desta amostra - Alemanha, Bélgica e Holanda -, denominados de fronteira tecnológica para fins de comparação neste artigo, aparecem num grupo diametralmente oposto.

Quando a análise de correspondência é realizada para a dimensão setor-indicador, é possível verificar que, no caso dos países de desempenho inovativo baixo (Brasil, Hungria, Croácia e Sérvia), setores tecnologicamente dinâmicos, 
seguindo o critério de dinamismo tecnológico da OECD, estão classificados nas categorias baixo e médio baixo. Por outro lado, quando esta mesma análise é aplicada para o grupo de países da fronteira tecnológica (Alemanha, Bélgica e Holanda), os mesmos setores passam a ser agrupados nas categorias alto e médio alto. Tal fato revela a existência de um forte hiato tecnológico entre os dois grupos de países e, portanto, a necessidade do desenvolvimento de competências produtivas e tecnológicas para que os países pertencentes ao grupo de baixo dinamismo inovativo sejam capazes de competir com aqueles do grupo da fronteira no mercado internacional.

\section{Referências bibliográficas}

AMENDOLA, G.; DOSI, G.; PAPAGNI, E. The dynamics of industrial competitiveness. Weltwirtschaftliches Archiv, v. 129, n. 3, p. 451-471, Feb., 1993.

ANTIMIANI, A.; CONSTANTINI, V. Trade performances and technology in the enlarged European Union. Journal of Economic Studies, v. 40, n. 3, p. 355-389, 2013.

BELDERBOS, R.; DUVIVIER, F.; WYNEN, J. Innovation and export competitiveness: evidence from Flemish firms. [S.l.]: Steunpunt Ondernemen en Internationaal Ondernemen (STOIO), 2009 (Working paper).

BELL, M.; PAVITT, K. Technological accumulation and industrial growth: contrasts between developed and developing countries. Industrial and Corporate Change, v. 2, n. 2, p. 157-210, 1993.

BELL, M.; PAVITT, K. The development of technological capabilities. In: HAQUE, I. U. (Ed.). Trade, technology and international competitiveness. Washington: The World Bank, 1995. p. 69-101.

CANTWELL, J. Inovation and competitiveness. In: FAGERBERG, J. et al. The Oxford handbook of Innovation. Oxford: Oxford University Press 2005.

CASTELLACCI, F. Innovation and the competitiveness of industries: comparing the mainstream and the evolutionary approaches. Technological Forecasting \& Social Change, v. 75, p. 984-1006, 2008.

DAMIJAN, J. P.; KOSTEVC, C.; POLANEC, S. From innovation to exporting or vice versa? Causal link between innovation activity and exporting in Slovenian microdata. [S.1.]: MICRO-DYN.EU Sixth Framework Programme, 2008. (Working paper n. 05/08).DOSI, 
G.; SOETE, L. Technology gaps and cost-based adjustment: some explorations on the determinants of international competitiveness. Metroeconomica, v. 35, n. 3, p. 197-222, outubro 1983.

Technical change and international trade. In: DOSI, G.; FREEMAN, C.; NELSON, R. R.; SILVERBERG, G.; SOETE, L. (Ed.) Technical change and economic theory. Londres: Pinter Publishers, 1988. p. 401-431.

DOSI, G.; PAVITT, K.; SOETE, L. The economics of technical change and international trade. London: Harvester Wheatsheaf, 1990.

DOSI, G.; GRAZZI, M.; MOSCHELLA, D. Technology and costs in international competitiveness: from countries and sectors to firms. Sant'Anna School, April, 2014 (LEM Working Paper, n. 2014/10). EUROSTAT. Community Innovation Survey 2010. Luxemburgo: Eurostat, 2013.

FAGERBERG, J. Technology and international differences in growth rates. Journal of Economic Literature, v. 32, n. 3, p. 1147-1175, Sep. 1994.

. Technology, grow and competitiveness: selected essays. Cheltenham, UK: Edward Elgar Publishing, 2002.

FAGERBERG, J.; SRHOLEC, M. National innovation systems, capabilities and economic development. Research Policy, v. 37, n. 9, p. 1417-1435, Oct. 2008.

FAGERBERG, J.; SRHOLEC, M.; KNELL, M. The competitiveness of nations: why some countries prosper while others fall behind. World Development, v. 35, n. 10, p. 1595-1620, Oct., 2007.

FAGERBERG, J.; VERSPAGEN, B. One Europe or several? Causes and consequences of the European stagnation. In: WORKSHOP THE CHALLENGE FOR EUROPE IN A NEW AGE. Alborg, Mar. 2013.

GREENACRE, M; HASTIE, T. The geometric interpretation of correspondence analysis. Journal of the American Statistical Association, v. 82, p. 437-447, 1987.

GREENACRE, M. La pratica del análisis de correspondências. Bilbao: Fundación BBVA, 2008.

HAIR JR., J. F.; ANDERSON, R. E.; TATHAM, R. L.; BACK, W. C. Análise multivariada de dados. Porto Alegre: Bookman, 2005.

IBGE - Instituto Brasileiro de Geografia e Estatística. Pesquisa de Inovação: instruções para o preenchimento do questionário. Rio de Janeiro: IBGE, 2011.

. Pesquisa Industrial de Inovação Tecnológica 2011. Rio de Janeiro: IBGE, 2013. 
LALL, S. Competitiveness, technology and skills. Cheltenham, UK: Edward Elgar Publishing, 2001.

Technological capabilities and industrialization. World Development, v. 20, n. 2, p. 165-186, Feb. 1992.

MOREWY, D.; NELSON, R. Sources of industrial leadership: studies of seven industries. Cambridge, MA: Cambridge University Press, 1999.

NELSON, R. R. National Innovation Systems: a retrospective on a study. Industrial and Corporate Change, v. 1, n. 2, p. 347-374, 1993.

NELSON, R. R.; WINTER, S. G. An evolutionary theory of economic change. Cambridge, MA: Belknap Press of Harvard University Press, 1982.

OECD - Organisation for Economic Co-operation and Development. Technology and the Economy: the key relationships. Paris: OECD, 1992.

. Frascati manual: proposed standard practice for surveys on research and experimental development. Paris: OECD Publications Service, 2002.

. OECD science, technology and industry scoreboard. Paris: OECD Publishing, 2005. . Perspectives on global development 2013 - Industrial policy in a changing world. Paris: OECD Publishing, 2013.

PELAEZ, V.; MELO, M.; HOFMANN, R.; AQUINO, D. Fundamentos e microfundamentos da capacidade dinâmica da firma. Revista Brasileira de Inovação, v. 7, n. 1, p. 101-125, jan./ jun. 2008.

POSNER, M. V. International trade and technical change. Oxford Economic Papers, v. 13, n. 3, p. 323-341, Oct. 1961.

POSSAS, M. L. Estruturas de mercado em oligopólio. Economia e planejamento. São Paulo: Editora Hucitec, 1987.

POSSAS, S. Concorrência e competitividade. Notas sobre estratégia e dinâmica seletiva na economia capitalista. São Paulo: Hucitec, 1999.

SCHUMPETER, J. A. Capitalism, socialism and democracy. New York: Harper \& Row, 1942.

TEECE, D. J.; PISANO, G. Dynamic capabilities of firms: an introduction. Industrial and Corporate Change, v. 3, n. 3, p. 537-556, 1994.

TEECE, D. Explicating dynamic capabilities: the nature and microfoundations of (sustainable) enterprise performance. Strategic Management Journal, v. 28, n. 13, p. 1319-1350, 2007. 
TIDD, J.; BESSANT, J.; PAVITT, K. Gestão da inovação. 3. ed. Porto Alegre: Bookman, 2008. TIGRE, P. B. O papel da política tecnológica na promoção das exportações. In: PINHEIRO, A. C.; MARKWALD, R.; PEREIRA, L. V. (Org.) O desafio das exportaçôes. Rio de Janeiro: BNDES, 2002. p. 245-282. 


\section{ANEXO}

\section{Resultados dos indicadores de inovação considerando a dimensão país $\mathrm{x}$ setor}

TABELA 1

Indicadores de inovação nas empresas do setor de alimentos bebidas e tabaco

Países selecionados - 2008-2010

\begin{tabular}{l|rr|r|r|r|r|r|r|r|c}
\hline \multirow{2}{*}{\multicolumn{1}{c}{ Países }} & \multicolumn{5}{|c|}{$\mathbf{2 0 0 8}$} & \multicolumn{5}{c}{$\mathbf{2 0 1 0}$} \\
\cline { 2 - 11 } & PDI & PDE & GIN & EIN & PO & PDI & PDE & GIN & EIN & PO \\
\hline Brasil & $\mathbf{3 , 4}$ & $\mathbf{1 , 4}$ & $\mathbf{1 , 8}$ & $\mathbf{3 7 , 9}$ & $\mathbf{0 , 1}$ & $\mathbf{3 , 4}$ & $\mathbf{1 , 2}$ & $\mathbf{1 , 8}$ & $\mathbf{4 0 , 0}$ & $\mathbf{0 , 1}$ \\
Bélgica & 32,1 & 18,1 & 0,6 & 13,5 & 1,2 & 41,6 & 16,1 & 1,0 & 18,4 & 1,4 \\
República Checa & 21,3 & 9,1 & 1,6 & 11,1 & 0,1 & 20,1 & 8,3 & 1,3 & 12,1 & 0,1 \\
Alemanha & 21,3 & 8,2 & 0,9 & 11,2 & 0,2 & 18,2 & 3,7 & 0,9 & 19,5 & 0,2 \\
Espanha & 11,8 & 7,1 & 0,8 & 13,0 & 0,6 & 10,6 & 6,7 & 0,7 & 14,0 & 0,6 \\
França & 25,3 & 7,4 & 1,2 & 10,0 & 0,5 & 23,2 & 10,2 & 1,3 & 8,1 & 0,6 \\
Croácia & 16,9 & 9,9 & 1,8 & 6,7 & 0,1 & 24,3 & 12,9 & 1,0 & 7,8 & 0,2 \\
Itália & 13,2 & 3,4 & 1,1 & 9,7 & 0,4 & 20,5 & 3,2 & 1,2 & 11,0 & 0,4 \\
Hungria & 7,4 & 3,8 & 0,7 & 5,2 & 0,2 & 9,4 & 4,6 & 0,7 & 7,0 & 0,3 \\
Holanda & 20,6 & 11,3 & 2,0 & 15,7 & 1,0 & 30,2 & 12,5 & 1,1 & 17,1 & 1,3 \\
Média & $\mathbf{1 7 , 3}$ & $\mathbf{8 , 0}$ & $\mathbf{1 , 3}$ & $\mathbf{1 3 , 4}$ & $\mathbf{0 , 4}$ & $\mathbf{2 0 , 2}$ & $\mathbf{7 , 9}$ & $\mathbf{1 , 1}$ & $\mathbf{1 5 , 5}$ & $\mathbf{0 , 5}$ \\
Desvio padrão & $\mathbf{8 , 6}$ & $\mathbf{4 , 7}$ & $\mathbf{0 , 5}$ & $\mathbf{9 , 2}$ & $\mathbf{0 , 4}$ & $\mathbf{1 0 , 9}$ & $\mathbf{4 , 9}$ & $\mathbf{0 , 3}$ & $\mathbf{9 , 7}$ & $\mathbf{0 , 5}$ \\
\hline
\end{tabular}

Fonte: IBGE. Pesquisa de Inovação Tecnológica - Pintec 2011; Community Innovation Survey - CIS 2010. Elaboração dos autores.

TABELA 2

Indicadores de inovação nas empresas do setor de fabricação de celulose, papel e produtos de papel Países selecionados - 2008-2010

\begin{tabular}{l|r|r|r|r|r|r|r|r|r|c}
\hline \multirow{2}{*}{\multicolumn{1}{c}{ Países }} & \multicolumn{7}{c}{$\mathbf{2 0 0 8}$} & \multicolumn{5}{c}{$\mathbf{2 0 1 0}$} \\
\cline { 2 - 11 } & PDI & PDE & GIN & EIN & PO & PDI & PDE & GIN & EIN & PO \\
\hline Brasil & $\mathbf{2 , 4}$ & $\mathbf{1 , 6}$ & $\mathbf{2 , 0}$ & $\mathbf{3 5 , 2}$ & $\mathbf{0 , 3}$ & 7,5 & $\mathbf{0 , 8}$ & $\mathbf{1 , 4}$ & $\mathbf{1 9 , 3}$ & $\mathbf{0 , 4}$ \\
Bélgica & 10,2 & 10,9 & 5,5 & 13,1 & 0,8 & 51,6 & 19,8 & 0,7 & 82,4 & 0,6 \\
República Checa & 16,2 & 9,1 & 1,2 & 6,1 & 0,0 & 19,4 & 8,3 & 0,9 & 36,4 & 0,1 \\
Alemanha & 21,3 & 8,2 & 0,9 & 11,2 & 0,2 & 29,5 & 8,0 & 0,9 & 64,4 & 0,2 \\
Espanha & 10,3 & 3,1 & 1,3 & 18,1 & 0,4 & 8,6 & 4,6 & 0,4 & 36,1 & 0,3 \\
França & 33,7 & 9,1 & 1,2 & 13,5 & 0,5 & 31,9 & 14,5 & 2,5 & 39,9 & 0,6 \\
Croácia & 19,1 & 21,3 & 1,4 & 8,5 & 0,0 & 18,3 & 3,3 & 0,3 & 46,7 & 0,0 \\
Itália & 16,8 & 5,0 & 2,6 & 16,8 & 0,3 & 14,4 & 2,0 & 1,7 & 37,6 & 0,3 \\
Hungria & 6,5 & 3,6 & 3,4 & 6,5 & 0,1 & 4,3 & 6,1 & 0,7 & 20,9 & 0,3 \\
Holanda & 31,3 & 18,5 & 0,9 & 22,7 & 0,7 & 32,8 & 13,4 & 1,8 & 58,1 & 0,2 \\
Média & $\mathbf{1 6 , 8}$ & $\mathbf{9 , 0}$ & $\mathbf{2 , 0}$ & $\mathbf{1 5 , 2}$ & $\mathbf{0 , 3}$ & $\mathbf{2 1 , 8}$ & $\mathbf{8 , 1}$ & $\mathbf{1 , 1}$ & $\mathbf{4 4 , 2}$ & $\mathbf{0 , 3}$ \\
Desvio padráo & $\mathbf{1 0 , 1}$ & $\mathbf{6 , 5}$ & $\mathbf{1 , 5}$ & $\mathbf{8 , 8}$ & $\mathbf{0 , 3}$ & $\mathbf{1 4 , 6}$ & $\mathbf{6 , 1}$ & $\mathbf{0 , 7}$ & $\mathbf{1 9 , 5}$ & $\mathbf{0 , 2}$ \\
\hline
\end{tabular}

Fonte: IBGE. Pesquisa de Inovação Tecnológica - Pintec 2011; Community Innovation Survey - CIS 2010. Elaboração dos autores. 
TABELA 3

Indicadores de inovação nas empresas do setor de fabricação de produtos químicos

Países selecionados - 2008-2010

\begin{tabular}{l|c|c|c|c|c|c|c|c|c|c}
\hline \multirow{2}{*}{ Países } & \multicolumn{9}{|c|}{$\mathbf{2 0 0 8}$} & \multicolumn{5}{c}{$\mathbf{2 0 1 0}$} \\
\cline { 2 - 11 } & PDI & PDE & GIN & EIN & PO & PDI & PDE & GIN & EIN & PO \\
\hline Brasil & $\mathbf{2 2 , 4}$ & $\mathbf{4 , 3}$ & $\mathbf{2 , 1}$ & $\mathbf{5 8 , 1}$ & $\mathbf{1 , 1}$ & $\mathbf{2 5 , 7}$ & $\mathbf{1 , 9}$ & $\mathbf{2 , 0}$ & $\mathbf{3 1 , 2}$ & $\mathbf{1 , 4}$ \\
Bélgica & 58,2 & 37,9 & 1,2 & 14,5 & 2,7 & 67,2 & 36,5 & 1,2 & 75,9 & 2,8 \\
República Checa & 57,0 & 29,1 & 2,6 & 11,8 & 1,4 & 53,6 & 33,9 & 1,7 & 66,5 & 1,7 \\
Alemanha & 80,9 & 30,1 & 3,5 & 15,4 & 2,0 & 77,5 & 26,5 & 3,2 & 89,4 & 2,4 \\
Espanha & 46,6 & 20,9 & 1,7 & 25,3 & 2,3 & 40,6 & 18,6 & 1,1 & 63,3 & 2,1 \\
França & 61,7 & 27,4 & 3,3 & 18,8 & 3,0 & 60,9 & 35,0 & 1,8 & 70,4 & 3,2 \\
Croácia & 36,4 & 22,7 & 1,4 & 10,6 & 0,6 & 30,3 & 15,2 & 1,0 & 37,9 & 0,7 \\
Itália & 47,4 & 19,3 & 1,8 & 9,8 & 2,0 & 47,7 & 12,0 & 1,6 & 75,2 & 1,9 \\
Hungria & 27,1 & 11,6 & 0,3 & 21,3 & 2,3 & 32,0 & 9,2 & 1,2 & 43,8 & 1,5 \\
Holanda & 57,0 & 32,1 & 2,4 & 28,4 & 2,8 & 55,8 & 29,3 & 2,4 & 65,2 & 2,3 \\
Média & $\mathbf{4 9 , 5}$ & $\mathbf{2 3 , 5}$ & $\mathbf{2 , 0}$ & $\mathbf{2 1 , 4}$ & $\mathbf{2 , 0}$ & $\mathbf{4 9 , 1}$ & $\mathbf{2 1 , 8}$ & $\mathbf{1 , 7}$ & $\mathbf{6 1 , 9}$ & $\mathbf{2 , 0}$ \\
Desvio padrão & $\mathbf{1 7 , 5}$ & $\mathbf{1 0 , 0}$ & $\mathbf{1 , 0}$ & $\mathbf{1 4 , 3}$ & $\mathbf{0 , 8}$ & $\mathbf{1 7 , 0}$ & $\mathbf{1 2 , 1}$ & $\mathbf{0 , 7}$ & $\mathbf{1 8 , 5}$ & $\mathbf{0 , 7}$ \\
\hline
\end{tabular}

Fonte: IBGE. Pesquisa de Inovação Tecnológica - Pintec 2011; Community Innovation Survey - CIS 2010. Elaboração dos autores.

TABELA 4

Indicadores de inovação nas empresas do setor de fabricação de produtos farmoquímicos e farmacêuticos Países selecionados - 2008-2010

\begin{tabular}{l|c|c|r|r|r|r|r|r|r|r}
\hline \multirow{2}{*}{ Países } & \multicolumn{9}{|c|}{$\mathbf{2 0 0 8}$} & \multicolumn{6}{c}{$\mathbf{2 0 1 0}$} \\
\cline { 2 - 12 } & PDI & PDE & GIN & EIN & PO & PDI & PDE & GIN & EIN & PO \\
\hline Brasil & $\mathbf{2 9 , 1}$ & $\mathbf{1 1 , 8}$ & $\mathbf{3 , 5}$ & $\mathbf{6 3 , 7}$ & $\mathbf{0 , 6}$ & $\mathbf{3 0 , 0}$ & $\mathbf{1 4 , 6}$ & $\mathbf{3 , 8}$ & $\mathbf{2 0 , 5}$ & $\mathbf{1 , 9}$ \\
Bélgica & 76,6 & 61,7 & 30,5 & 8,5 & 8,4 & 70,0 & 36,7 & 30,4 & 78,3 & 10,9 \\
República Checa & 44,9 & 51,0 & 5,1 & 65,3 & 2,8 & 64,9 & 43,9 & 6,8 & 71,9 & 2,6 \\
Alemanha & 76,7 & 52,2 & 11,2 & 20,5 & 4,6 & 70,1 & 49,7 & 10,5 & 85,2 & 5,5 \\
Espanha & 65,1 & 48,2 & 5,4 & 27,1 & 5,1 & 61,4 & 49,2 & 4,6 & 78,7 & 4,8 \\
França & 53,2 & 47,5 & 5,2 & 21,1 & 4,9 & 75,4 & 68,9 & 7,9 & 81,1 & 3,8 \\
Croácia & 70,0 & 40,0 & 13,6 & 10,0 & 5,0 & 50,0 & 35,7 & 7,3 & 50,0 & 3,7 \\
Itália & $\mathbf{6 9 , 0}$ & 39,0 & 3,2 & 27,3 & 3,1 & 57,8 & 42,2 & 3,6 & 75,2 & 3,2 \\
Hungria & 47,5 & 30,0 & 9,8 & 12,5 & 9,0 & 43,2 & 22,7 & 9,4 & 56,8 & 10,5 \\
Holanda & 47,0 & 42,4 & 16,8 & 25,8 & 8,9 & 70,1 & 37,3 & 13,9 & 76,1 & 6,8 \\
Média & $\mathbf{5 7 , 9}$ & $\mathbf{4 2 , 4}$ & $\mathbf{1 0 , 4}$ & $\mathbf{2 8 , 2}$ & $\mathbf{5 , 2}$ & $\mathbf{5 9 , 3}$ & $\mathbf{4 0 , 1}$ & $\mathbf{9 , 8}$ & $\mathbf{6 7 , 4}$ & $\mathbf{5 , 4}$ \\
Desvio padrão & $\mathbf{1 5 , 9}$ & $\mathbf{1 3 , 8}$ & $\mathbf{8 , 4}$ & $\mathbf{2 0 , 3}$ & $\mathbf{2 , 8}$ & $\mathbf{1 4 , 4}$ & $\mathbf{1 5 , 0}$ & $\mathbf{7 , 9}$ & $\mathbf{1 9 , 8}$ & $\mathbf{3 , 1}$ \\
\hline
\end{tabular}

Fonte: IBGE. Pesquisa de Inovação Tecnológica - Pintec 2011; Community Innovation Survey - CIS 2010. Elaboração dos autores. 
TABELA 5

Indicadores de inovação nas empresas do setor de fabricação de artigos de borracha e plástico

Países selecionados - 2008-2010

\begin{tabular}{l|rr|r|r|r|r|r|r|r|r}
\hline \multirow{2}{*}{ Países } & \multicolumn{9}{|c|}{$\mathbf{2 0 0 8}$} & \multicolumn{5}{c}{$\mathbf{2 0 1 0}$} \\
\cline { 2 - 11 } & PDI & PDE & GIN & EIN & PO & PDI & PDE & GIN & EIN & PO \\
\hline Brasil & $\mathbf{5 , 9}$ & $\mathbf{5 , 9}$ & $\mathbf{2 , 4}$ & $\mathbf{3 6 , 3}$ & $\mathbf{0 , 3}$ & $\mathbf{6 , 4}$ & $\mathbf{1 , 4}$ & $\mathbf{2 , 6}$ & $\mathbf{1 4 , 0}$ & $\mathbf{0 , 3}$ \\
Bélgica & 56,5 & 23,2 & 2,1 & 19,7 & 2,5 & 48,6 & 34,3 & 2,1 & 72,1 & 2,7 \\
República Checa & 22,3 & 12,0 & 2,4 & 10,2 & 0,4 & 26,0 & 15,7 & 2,1 & 44,3 & 0,5 \\
Alemanha & 49,2 & 13,1 & 1,9 & 12,7 & 1,1 & 49,5 & 15,2 & 1,9 & 78,3 & 1,2 \\
Espanha & 16,3 & 7,4 & 1,2 & 19,6 & 0,7 & 15,7 & 8,6 & 1,2 & 42,5 & 0,7 \\
França & 36,4 & 13,1 & 2,8 & 19,2 & 2,0 & 37,5 & 15,9 & 2,3 & 47,3 & 1,9 \\
Croácia & 24,6 & 12,3 & 4,4 & 23,1 & 0,0 & 31,9 & 14,5 & 3,4 & 51,2 & 0,1 \\
Itália & 30,5 & 7,6 & 1,5 & 14,8 & 0,4 & 23,9 & 9,2 & 1,8 & 49,6 & 0,4 \\
Hungria & 12,4 & 4,3 & 0,7 & 10,8 & 0,2 & 8,6 & 4,7 & 0,3 & 18,7 & 0,3 \\
Holanda & 55,2 & 30,0 & 1,5 & 27,9 & 0,4 & 48,3 & 18,7 & 1,6 & 65,8 & 2,2 \\
Média & $\mathbf{3 0 , 9}$ & $\mathbf{1 2 , 9}$ & $\mathbf{2 , 1}$ & $\mathbf{1 9 , 4}$ & $\mathbf{0 , 8}$ & $\mathbf{2 9 , 6}$ & $\mathbf{1 3 , 8}$ & $\mathbf{1 , 9}$ & $\mathbf{4 8 , 4}$ & $\mathbf{1 , 0}$ \\
Desvio padráo & $\mathbf{1 8 , 0}$ & $\mathbf{8 , 0}$ & $\mathbf{1 , 0}$ & $\mathbf{8 , 1}$ & $\mathbf{0 , 8}$ & $\mathbf{1 6 , 3}$ & $\mathbf{9 , 1}$ & $\mathbf{0 , 8}$ & $\mathbf{2 0 , 8}$ & $\mathbf{0 , 9}$ \\
\hline
\end{tabular}

Fonte: IBGE. Pesquisa de Inovação Tecnológica - Pintec 2011; Community Innovation Survey - CIS 2010. Elaboração dos autores.

TABELA 6

Indicadores de inovação nas empresas do setor de metalurgia e siderurgia

Países selecionados - 2008-2010

\begin{tabular}{|c|c|c|c|c|c|c|c|c|c|c|}
\hline \multirow{2}{*}{ Países } & \multicolumn{5}{|c|}{2008} & \multicolumn{5}{|c|}{2010} \\
\hline & PDI & PDE & GIN & EIN & PO & PDI & PDE & GIN & EIN & PO \\
\hline Brasil & 3,4 & 3,8 & 2,2 & 39,5 & 0,4 & 5,6 & 0,9 & 2,6 & 21,2 & 0,7 \\
\hline Bélgica & 45,7 & 29,5 & 1,5 & 31,4 & 1,3 & 52,3 & 46,2 & 1,6 & 55,4 & 1,7 \\
\hline República Checa & 31,2 & 24,2 & 2,2 & 13,0 & 0,3 & 29,3 & 17,2 & 0,8 & 47,0 & 0,3 \\
\hline Alemanha & 46,7 & 26,5 & 1,7 & 16,9 & 0,6 & 44,6 & 19,8 & 1,3 & 71,8 & 0,8 \\
\hline Espanha & 18,7 & 11,1 & 0,6 & 19,4 & 1,3 & 22,4 & 11,6 & 0,6 & 52,4 & 0,8 \\
\hline França & 37,0 & 22,6 & 3,5 & 25,1 & 1,5 & 39,9 & 27,0 & 1,6 & 50,9 & 1,5 \\
\hline Croácia & 27,0 & 10,8 & 5,1 & 32,4 & 0,0 & 27,0 & 10,8 & 5,1 & 32,4 & 0,0 \\
\hline Itália & 19,7 & 6,6 & 1,1 & 21,6 & 0,4 & 26,2 & 17,6 & 0,9 & 46,4 & 0,2 \\
\hline Hungria & 12,5 & 4,5 & 0,2 & 14,3 & 0,4 & 17,4 & 14,7 & 0,2 & 28,4 & 0,6 \\
\hline Holanda & 44,6 & 20,7 & 2,2 & 19,8 & 1,6 & 46,8 & 16,9 & 2,1 & 48,4 & 2,7 \\
\hline Média & 28,7 & 16,0 & 2,0 & 23,4 & 0,8 & 31,1 & 18,3 & 1,7 & 45,4 & 1,0 \\
\hline Desvio padrão & 15,0 & 9,7 & 1,4 & 8,6 & 0,6 & 14,6 & 11,9 & 1,4 & 14,6 & 0,8 \\
\hline
\end{tabular}


